\title{
Metformin in advanced chronic kidney disease: are current guidelines overly restrictive?
}

\author{
NICHOLAS I COLE, PAULINE A SWIFT, REBECCA J SUCKLING, PETER A ANDREWS
}

\begin{abstract}
Type 2 diabetes mellitus and chronic kidney disease (CKD) frequently co-exist and the increasing burden of both conditions is a global concern. Metformin is established as the first-line treatment for type 2 diabetes because it is associated with improved cardiovascular outcomes and a reduced risk of hypoglycaemia compared with other treatment options. Patients with CKD may benefit in particular because they are at high risk of both cardiovascular disease and hypoglycaemic episodes. However, the use of metformin is restricted in this population due to the concerns over lactic acidosis. Recent reviews have evaluated this risk and concluded that current guidelines for prescribing metformin in CKD may be too restrictive. This narrative review considers this evidence further, but also examines the strength of evidence that favours the use of metformin in CKD patients. Br J Diabetes 2016;16:168-175
\end{abstract}

Key words: type 2 diabetes mellitus, chronic kidney disease, metformin, biguanides, lactic acidosis, lactate, cardiovascular disease, hypoglycaemia

\section{Introduction}

Chronic kidney disease (CKD) commonly co-exists with diabetes mellitus; the estimated prevalence of Kidney Disease Outcomes Quality Initiative (KDOQI) stage 3-5 CKD in the UK for those with diabetes is $31 \% .{ }^{1}$ Diabetic nephropathy is the most common attributed cause of end-stage renal disease (ESRD) in those starting dialysis in the UK, with an incidence of $25.4 \% .{ }^{2}$ Overt diabetic nephropathy most often occurs 15-20 years after the onset of diabetes and frequently occurs alongside other diabetic microvascular complications such as neuropathy and retinopathy. ${ }^{3}$ In addition, macrovascular disease is highly prevalent because both diabetes and CKD are important risk factors for developing cardiovascular disease (CVD).4,5

The increasing burden of type 2 diabetes is a global concern.

South West Thames Renal Department, Epsom and St Helier University Hospitals, Surrey, UK

Address for correspondence: Dr Nicholas Cole Renal Department, St Helier Hospital, Wrythe Lane, Carshalton, Surrey SM5 1AA, UK

Tel: +44 (0)7758217166 Fax: +44 (0)2082962857

E-mail: nicholascole@nhs.net

http://dx.doi.org/10.15277/bjd.2016.106
The International Diabetes Federation (IDF) estimates that 387 million people worldwide (8.3\% of the global population) have diabetes. ${ }^{6}$ Type 2 diabetes accounts for $85-95 \%$ of diabetes in high-income countries and the prevalence of this disease is increasing. If current trends continue, the IDF calculates a global burden of 592 million people ( 1 in 10 adults) by 2035. Establishing optimal treatment may therefore produce significant benefits on a population level.

Treatment of type 2 diabetes in those with CKD is aimed at reducing microvascular and macrovascular complications, including the progression of kidney disease. However, management options are restricted because reduced kidney function restricts the use of certain oral hypoglycaemic agents. This is particularly the case with metformin, a biguanide drug that has been established as the firstline treatment for type 2 diabetes in the general population, but which most current guidelines consider to be contraindicated in those with advanced CKD. . $^{7-9}$ This is largely due to the perceived increased risk of lactic acidosis, a rare but potentially life-threatening complication associated with biguanide therapy. In addition, a recent observational study has found metformin to be associated with greater mortality in patients approaching ESRD (CKD stage 5). ${ }^{10}$

Recent reviews have focused on metformin and the risk of lactic acidosis in patients with CKD.11,12 They concluded that the risk of this complication has been overemphasised in this group and that the current prescribing guidelines may be too restrictive. However, these reviews did not fully consider the strength of evidence that favours the use of metformin in patients with CKD. This narrative review will summarise the evidence for and against metformin use in this population.

Search strategy and selection criteria

References for this review were identified through searches of PubMed for articles published from January 1970 to September 2015, by use of the terms "kidney", "renal", "CKD", "GFR", and "glomerular filtration rate", in combination with the terms "diabetes" and "metformin". Only articles published in English were included. Articles resulting from these searches and relevant references cited in those articles were reviewed.

The importance of glycaemic control

Metformin is the first-line hypoglycaemic drug for those with type 2 diabetes. ${ }^{7,8}$ Its glucose-lowering effect is attributed to increased insulin sensitivity, decreased hepatic glucose output and enhanced peripheral glucose uptake. ${ }^{13}$ The importance of glycaemic control has been demonstrated in large trials that have shown a reduction in diabetic microvascular complications. In 
the landmark United Kingdom Prospective Diabetes Study (UKPDS), over 4,000 participants with newly diagnosed type 2 diabetes were randomly assigned to receive conventional dietbased therapy or intensive glycaemic control with a sulphonylurea or insulin. ${ }^{14}$ Mean glycated haemoglobin $\left(\mathrm{HbA}_{1 \mathrm{c}}\right)$ was $7.0 \%(53 \mathrm{mmol} / \mathrm{mol})$ in the intensive group and $7.9 \%(63$ $\mathrm{mmol} / \mathrm{mol}$ ) in the conventional group. Over 10 years, intensive therapy substantially reduced the risk of diabetic microvascular complications by $25 \%$. This effect persisted at a further 10 years post-trial, despite the differences in $\mathrm{HbA}_{1 \mathrm{c}}$ levels being lost after a year. ${ }^{15}$ In addition, there was a $15 \%(p=0.01)$ risk reduction for myocardial infarction and a $13 \%(p=0.007)$ risk reduction for death from any cause in the intensive glycaemic control group.

The association of reduced microvascular complications with improved glycaemic control is of particular relevance in the CKD population because of the potential to slow the progression of diabetic nephropathy. The Action in Diabetes and Vascular Disease: Preterax and Diamicron Modified Release Controlled Evaluation (ADVANCE) trial randomised 11,140 patients with type 2 diabetes to undergo standard glucose control (mean $\mathrm{HbA}_{1 \mathrm{c}}$ $7.4 \%$ or $57 \mathrm{mmol} / \mathrm{mol}$ ) or intensive glucose control (mean $\mathrm{HbA}_{1 \mathrm{c}}$ $6.5 \%$ or $48 \mathrm{mmol} / \mathrm{mol}) .{ }^{16}$ At baseline the mean creatinine was normal, $27 \%$ had microalbuminuria and 3.6\% had macroalbuminuria. There was a significantly lower incidence of major microvascular events in the intensive control group over a median follow-up of five years, primarily due to a reduction in the incidence of nephropathy. The use of most classes of oral hypoglycaemic and insulin had increased in the intensive treatment group. Later analysis revealed significant reductions in the risk of developing ESRD (65\%), microalbuminuria (9\%) and macroalbuminuria (30\%). ${ }^{17}$ Furthermore, the progression of albuminuria was significantly reduced by $10 \%$ and its regression significantly increased by $15 \%$. The number needed to treat over five years to prevent one ESRD event ranged from 410 in the overall study to 41 in participants with pre-existing macroalbuminuria. In support of these findings, another trial - the Veterans Affairs Diabetes Trial (VADT) - also demonstrated a benefit in reducing microalbuminuria with intensive glycaemic control. ${ }^{18}$

There are limited data in those with more advanced CKD, and it is uncertain whether glycaemic control is as effective for this group of patients, many of whom have established diabetic complications. Observational studies have associated glycaemic control with improved outcomes but they do not establish causality. ${ }^{19-21}$

\section{Implications of current recommendations}

It is now widely acknowledged that the US Food and Drug Administration prescribing guidelines for metformin are too restrictive. They state that its use is contraindicated with a creatinine $>1.5 \mathrm{mg} / \mathrm{dL}(133 \mu \mathrm{mol} / \mathrm{L})$ in men or $>1.4 \mathrm{mg} / \mathrm{dL}(124 \mu \mathrm{mol} / \mathrm{L})$ in women. 22 This approximately equates to an estimated glomerular filtration rate (eGFR) of $<45 \mathrm{~mL} / \mathrm{min}$, or CKD stage $3 B$ or more. In the UK, the British National Formulary states that metformin should be used "with caution in renal impairment" and should be avoided "in significant renal impairment". 9 The National Institute for Health and Care Excellence (NICE) recommends that the dose of metformin is reviewed if the creatinine exceeds $130 \mu \mathrm{mol} / \mathrm{L}$ or eGFR falls to $<45 \mathrm{~mL} / \mathrm{min}$. $^{7} \mathrm{NICE}$ goes on to recommend that metformin is stopped once serum creatinine exceeds $150 \mu \mathrm{mol} / \mathrm{L}$ or if the eGFR is $<30 \mathrm{~mL} / \mathrm{min}$ (CKD stage 4 or more). In the USA the American Diabetes Association is in agreement with this position. ${ }^{23}$

It is uncertain whether these recommendations are adhered to and there is likely to be variability in prescribing practice. There are few data available to estimate the additional number of patients who may benefit from metformin therapy if its use was to be expanded in those with more advanced CKD. Dreyer et al performed a cross-sectional study of 34,359 patients with diabetes in three primary care trusts in the UK. ${ }^{24}$ They found that the prevalence of people with an eGFR of $<45 \mathrm{~mL} / \mathrm{min}$ was $5.4 \%$. However, this may be an underestimate because the study population contained a significant number of non-white individuals (who have a lower prevalence of CKD stage 3). Indeed, Bailey et al used National Health and Nutrition Examination Survey (NHANES) data to find a prevalence of $9 \%$ in the USA, whilst a study from Spain estimated the prevalence to be $6.4 \% .25,26$ Given the large burden of type 2 diabetes, these data suggest that there are a large number of diabetics with CKD who might benefit from even a mild relaxation of the eGFR cut-off for continuing metformin.

\section{The case for metformin use in CKD}

\section{Improved cardiovascular outcomes}

Metformin has become firmly established as the first-line oral hypoglycaemic agent in patients with type 2 diabetes mellitus, in large part due to the UKPDS. The original study found intensive therapy with a sulphonylurea or insulin reduced the risk of diabetic microvascular complications but not macrovascular disease when compared with conventional treatment. ${ }^{14}$ This is in keeping with the results of the ADVANCE trial that also showed no reduction in cardiovascular events with intensive glycaemic control. ${ }^{16}$ However, in the UKPDS, metformin was included as a randomisation option in 1,704 participants who were overweight. ${ }^{27}$ Only 342 individuals received metformin, but they were found to have a $39 \%$ lower risk ( $p=0.010$ ) of myocardial infarction compared with conventional treatment. They also had a $30 \%$ lower risk ( $p=0.020$ ) of all macrovascular disease including myocardial infarction, sudden death, angina, stroke and peripheral vascular disease. The risk reduction in the metformin group was greater than in those assigned intensive therapy with a sulphonylurea or insulin, although the difference was not statistically significant. It should be noted that other trials have failed to show reductions in cardiovascular events or mortality with metformin therapy, but these have been of shorter duration than the UKPDS. ${ }^{28-30}$

A number of mechanisms have been proposed to explain the improved cardiovascular outcomes observed with metformin, including weight loss and an improved lipoprotein profile. ${ }^{13,28}$ These effects may be of particular benefit in CKD because the risk of CVD increases as renal disease becomes more ad- 
vanced. ${ }^{31-33}$ However, it is by no means certain that the findings of the UKPDS is applicable to CKD patients because it examined metformin use in a small subgroup of overweight patients who did not have established CVD. This is in contrast to the CKD population, which has a complex cardiovascular risk profile that includes traditional risk factors as well as atypical factors such as vascular calcification. In a prospective observational study, Ekström et al examined metformin therapy in 51,675 patients with type 2 diabetes and differing levels of renal function (eGFR 30-44 mL/min, 45-59 mL/min and $\geq 60 \mathrm{~mL} / \mathrm{min}$ ). ${ }^{34}$ In this study, metformin-based therapy was not associated with a reduced risk of CVD when compared with other therapies, independent of renal function.

The above notwithstanding, there is evidence that metformin may be beneficial for those with pre-existing cardiovascular disease. In a trial of 304 people with type 2 diabetes and coronary artery disease, metformin monotherapy significantly reduced composite cardiovascular events in comparison to glipizide over five years of follow-up (HR 0.54, 95\% Cl 0.30 to 0.90). ${ }^{35}$ Furthermore, Roussel et al examined data from 19,691 participants with diabetes and established atherothrombosis in the Reduction of Atherothrombosis for Continued Health (REACH) registry. ${ }^{36}$ They found that mortality was lower for patients with an eGFR $\geq 30 \mathrm{~mL} / \mathrm{min}$ who had been prescribed metformin compared with those who were not. Statistical significance was reached only in those with an eGFR $<60 \mathrm{~mL} / \mathrm{min}$ and there was a greater reduction in mortality in the group with an eGFR of $30-44 \mathrm{~mL} / \mathrm{min}$ (HR $0.57,95 \% \mathrm{Cl} 0.35$ to 0.92 ) than for the group with an eGFR of $45-59 \mathrm{~mL} / \mathrm{min}$ (HR $0.75,95 \% \mathrm{Cl} 0.52$ to 1.10$)$.

\section{Fewer hypoglycaemic episodes}

A well-established benefit of metformin therapy compared with most other oral hypoglycaemic agents is the lower risk of hypoglycaemia. ${ }^{37}$ The Action to Control Cardiovascular Risk in Diabetes (ACCORD) study compared intensive glucose control (mean $\mathrm{HbA}_{1 \mathrm{c}} 6.4 \%$ or $46 \mathrm{mmol} / \mathrm{mol}$ ) with standard glucose control (mean $\mathrm{HbA}_{1 \mathrm{c}} 7.5 \%$ or $59 \mathrm{mmol} / \mathrm{mol}$ ) in patients with type 2 diabetes. ${ }^{38}$ The study was stopped after 3.5 years due to a significantly higher mortality rate in the intensive therapy group. Although a direct link was not established, there was a significantly higher rate of hypoglycaemia in the intensive therapy group, a finding that was in common with the ADVANCE study and VADT. ${ }^{16,18}$ Hypoglycaemia is a potentially life-threatening complication of diabetes treatment and recent observational data have found an association between hypoglycaemia in insulin-treated patients and increased cardiovascular risk. ${ }^{39}$

Hypoglycaemia is particularly important for those with CKD because it occurs more frequently. ${ }^{40}$ This is likely due to a combination of reduced insulin clearance, lower glycogen stores, decreased renal gluconeogenesis and reduced clearance of hypoglycaemic medication. For this reason, international guidelines have recommended less stringent glycaemic control targets for patients with CKD than for those without CKD. ${ }^{41,42}$ Indeed, in a post hoc analysis of the ACCORD data, intensive glycaemic control was found to significantly increase cardiovascular and all-cause mortality in CKD patients, but not in non-CKD patients. ${ }^{43}$ Therefore, metformin may have a particular advantage over other therapies in this high-risk population.

\section{Disadvantages of other treatment options}

Metformin may have additional advantages over other hypoglycaemic agents including a lower risk of renal function decline and of solid cancers. ${ }^{44,45}$ However, it is also important to consider the specific disadvantages of the alternative treatment options. Although the treatment of diabetes is evolving, many agents are contraindicated or unlicensed for use in advanced CKD. ${ }^{9}$ Other drugs such as the dipeptidylpeptidase-4 inhibitors lack long-term and hard outcome data, whilst pioglitazone has been associated with heart failure and bladder cancer (although a recent pooled analysis has challenged the latter). ${ }^{46,47}$ Therefore, when metformin is contraindicated, the alternative is often to switch to a sulphonylurea or insulin. Both of these are associated with weight gain, an important side-effect that has implications for both body image and cardiovascular risk. Insulin in particular is unpopular with patients and associated with its own risks and costs. Indeed, observational studies have associated adverse cardiovascular outcomes and increased mortality with both sulphonyureas and insulin, albeit the data from clinical trials are less conclusive. ${ }^{48,49}$

This is not to say that metformin does not have its own problems: in addition to the association with lactic acidosis, gastrointestinal side-effects limit its tolerability in some patients and it has been associated with vitamin B12 deficiency.9.50 But when tolerated and appropriately monitored, metformin is cheap, simple to administer and safe.

\section{The case against metformin use in CKD}

\section{The risk of lactic acidosis}

Metformin and phenformin, the two main biguanides, were introduced in the late 1950s but the latter was withdrawn in many countries in the late 1970s due to its association with lactic acidosis. ${ }^{13}$ Metformin also causes a small increase in serum lactate concentrations, probably because of conversion of glucose to lactate by the intestinal mucosa and reduced uptake of lactate in the liver. ${ }^{12,51-53}$ However, significant lactic acidosis associated with metformin use is rare and has been overemphasised in the literature. In a meta-analysis of 347 comparative trials and cohort studies, no cases of lactic acidosis were identified in 70,490 patient-years of metformin use. ${ }^{54}$ Individual studies have reported crude incidence rates of 3.3-10.4 cases per 100,000 patient-years. ${ }^{37,55-58}$ This risk may be comparable to rates of lactic acidosis in those taking sulphonylureas or in those with type 2 diabetes in general. ${ }^{37,56}$

Metformin is primarily eliminated unchanged by the kidneys and therefore kidney disease is associated with higher drug levels that could increase the risk of lactic acidosis as renal function declines. ${ }^{59,60}$ Metformin has also been shown to accumulate in enterocytes of the small intestine in a mouse model of diabetes. ${ }^{61}$ This may explain the long half-life of metformin elimination in cases of metformin-associated lactic acidosis and may 
be of particular concern in those with CKD. ${ }^{62}$ Indeed, case reports have frequently identified kidney failure (both acute and chronic) as a risk factor. $63-65$ Despite this, only a few experimental studies have tried to establish whether reduced metformin clearance in CKD is associated with an increased serum lactate level. In the only randomised control trial, Rachmani et al randomly assigned 393 type 2 diabetics with a serum creatinine of 130$200 \mu \mathrm{mol} / \mathrm{L}$ to continue or stop metformin. ${ }^{66}$ A close correlation between serum creatinine and lactate levels was observed $(r=0.78, p<0.001)$. In other small studies, however, this correlation has not been seen. ${ }^{67,68}$ The relevance of these experimental findings is uncertain, given the rarity of significant metforminassociated lactic acidosis in clinical practice. For instance, in the large meta-analysis mentioned above, $45 \%$ of the studies reviewed did not exclude patients with a creatinine of $>133$ $\mu \mathrm{mol} / \mathrm{L} .{ }^{54}$ This meant there were no cases of metformin-associated lactic acidosis identified amongst 37,360 patient-years of metformin use in patients with CKD.

To further determine the risks of metformin use with kidney disease, retrospective observational studies have investigated the frequency of lactic acidosis in those with CKD. In the aforementioned study by Ekström et al, metformin prescription was not associated with an increased risk of acidosis or serious infection in patients with an eGFR of 30-44 mL/min when compared with other hypoglycaemic treatments. ${ }^{34}$ Conversely, metformin was associated with a significantly lower risk of this composite outcome compared with other agents in those with an eGFR $\geq 45$ $\mathrm{mL} / \mathrm{min}$. In a recent study by Hung et al, metformin use in 3,254 patients with advanced CKD approaching ESRD (creatinine $>530$ $\mu \mathrm{mol} / \mathrm{L}$ ) was not associated with a significantly greater risk of metabolic acidosis (adjusted HR 1.30, 95\% Cl 0.88 to 1.93). ${ }^{10}$

Two large studies have analysed UK patient records from the Clinical Practice Research Datalink (CPRD) database. Richy et al examined the records of 77,601 patients treated with metformin for type 2 diabetes between 2007 and 2012.57 They found no statistically significant increase in the incidence of lactic acidosis in patients with more advanced CKD compared to those with normal renal function. Eppenga et al investigated a larger cohort of 223,968 patients with type 2 diabetes prescribed metformin between 2004 and 2012.58 Evaluating lactic acidosis either by CPRD Read code or a serum lactate concentration of $>5 \mathrm{mmol} / \mathrm{L}$, they found an overall crude incidence rate of metformin-associated lactic acidosis of 7.4 events per 100,000 patient-years. Metformin users with an eGFR $\geq 60 \mathrm{~mL} / \mathrm{min}$ did not have a significantly increased risk of lactic acidosis compared with those never prescribed metformin (adjusted HR 2.87, 95\% Cl 0.67 to 12.3). The risk, however, was significantly higher for metformin users with an eGFR $<60 \mathrm{~mL} / \mathrm{min}$ (adjusted HR 6.37, 95\% Cl 1.48 to 27.5 ). What is interesting to note, particularly from the point of view of current guidelines, is that the risk for those with an eGFR 30-44 mL/min (adjusted HR 5.47, 95\% Cl 1.05 to 28.5) was comparable to those with an eGFR of $45-59 \mathrm{~mL} / \mathrm{min}$ (adjusted HR $6.06,95 \% \mathrm{Cl} 1.37$ to 27.1$)$. The crude incidence of lactic acidosis in metformin users with an eGFR of $30-59 \mathrm{~mL} / \mathrm{min}$ (i.e. for patients with CKD stage 3) was 15.3 events per 100,000 patient-years. These data suggest that, although the relative risk of lactic acidosis in those taking metformin does increase with $C K D$, the absolute risk remains low.

Following on from this, it is reasonable to question whether the excess risk of metformin-associated lactic acidosis in CKD patients can by offset by reducing the dose of metformin as opposed to stopping it. In the study by Eppenga et al, the risk of lactic acidosis was lower in those prescribed smaller doses of metformin, especially in those with an eGFR $<60 \mathrm{~mL} / \mathrm{min} .{ }^{58}$ There is also experimental evidence to support this finding. In a study of 24 patients aged $70-88$ years, those with a creatinine clearance $(\mathrm{CrCl})$ of $>60 \mathrm{~mL} / \mathrm{min}$ were prescribed $1,700 \mathrm{mg} /$ day metformin and those with a $\mathrm{CrCl}$ of $30-60 \mathrm{~mL} / \mathrm{min}$ were prescribed $850 \mathrm{mg} /$ day. After two months there was no significant difference in the serum levels of metformin and lactate between the two groups. ${ }^{69}$ Similarly, Lin et al compared lactate levels in 66 patients with type 2 diabetes aged over 80 years and taking metformin (mean age 83.6 years, mean $\mathrm{CrCl} 48.9 \mathrm{~mL} / \mathrm{min}$ ) with 79 younger individuals (mean age 59.9 years, mean $\mathrm{CrCl} 80.3$ $\mathrm{mL} / \mathrm{min}$ ). There was no difference between the groups, although it should be recognised that the patients in the elderly group had a significantly lower daily metformin dose. ${ }^{70}$ However, the evidence does not support the routine measurement of serum lactate to guide metformin dosing in CKD. In a study of 22 patients with eGFR readings of $15-40 \mathrm{~mL} / \mathrm{min}$ (as well as two dialysis patients), three patients developed a high lactate concentration (>2.7 mmol/L) but no correlation was observed with the serum metformin level. ${ }^{71}$

The lack of a clinically useful relationship between metformin levels and lactate concentration in those with CKD has also been demonstrated elsewhere.66,72 The explanation for this finding is that there is unlikely to be a simple causal relationship. The difficulty with interpreting the studies using CPRD data is their observational nature and the fact that there are other causes of lactic acidosis. In a series of 49 metformin-treated patients with lactic acidosis, Lalau and Race found that neither serum metformin levels nor lactate levels were of prognostic value with regard to mortality. ${ }^{73}$ They concluded that death in these patients appeared to be associated with other hypoxic injury or underlying ill health rather than the accumulation of metformin. Patients with both diabetes and CKD frequently have other co-morbidities that predispose to lactic acidosis, irrespective of the use of metformin. These include more advanced diabetes and CVD, both of which may predispose to sepsis and/or vascular insufficiency. In addition, these patients are at increased risk of acute kidney injury $(\mathrm{AKI}) .{ }^{74} \mathrm{AKI}$ is frequently associated with acute presentations that can result in lactic acidosis (e.g. sepsis, ischaemia, hypovolaemia), as well as being an independent risk factor for the accumulation of metformin due to reduced renal excretion.

Further support for the view that metformin use is not an isolated risk factor for developing lactic acidosis was found in a study by Bodmer et al. ${ }^{37}$ They examined the records of 50,048 patients with type 2 diabetes from the UK General Practice Research Database between 1994 and 2005 and identified only seven cases of lactic acidosis, of which five were in current users 
of metformin. In four of these, lactic acidosis was associated with the worsening of other factors known to contribute to the risk of lactic acidosis: acute heart failure, urosepsis, AKI, hypovolaemia or seizure. Similarly, in a review of 47 cases of metformin-associated lactic acidosis, a panel of six critical care experts came to the conclusion that there was not a simple causal relationship between metformin use and lactic acidosis in diabetic patients. ${ }^{63}$ It therefore may be more logical and sufficient to suggest that metformin be stopped in specific groups of patients at high risk of lactic acidosis rather than avoiding its use in all patients with CKD.

\section{A lack of evidence for metformin in CKD}

It is important to note that there have been no comparative trials in the CKD population in order to establish the potential benefit of metformin compared with alternative treatment options. This group differs substantially from the majority of participants in these studies because patients with kidney disease frequently have long-standing diabetes with established complications, as well as atypical cardiovascular risk factors. Indeed, in the aforementioned study by Hung et al, metformin was associated with increased mortality in those with advanced CKD approaching ESRD (KDIGO CKD stage 5) that was not explained by an increased risk of acidosis. ${ }^{10}$ This is in contrast to observational studies in the wider population that have shown metformin monotherapy to be associated with lower mortality compared with other hypoglycaemic agents. 75,76 Interpreting this study should be done with caution, given the observational design and potential for confounding factors. Nevertheless, it may be incorrect to assume that the results of trials that have established the benefits of metformin therapy, as well as glycaemic control in general, apply to those with CKD.

The UKPDS remains the most important of these studies, but the trial results have attracted some controversy. Boussageon et al point out that the beneficial effects of metformin were limited to a small subgroup of overweight patients and that these findings have not been replicated in other studies. ${ }^{77,78}$ They highlight methodological flaws in the study, particularly the lack of double blinding and a placebo control. Another concern has been the paradoxical finding that all-cause mortality was higher when metformin was added to a sulphonylurea compared with a sulphonylurea alone (RR 1.60, $95 \% \mathrm{Cl} 1.02$ to 2.52 ). ${ }^{27}$ In support of this, a meta-analysis of observational studies reported an increased risk of cardiovascular hospitalisation and mortality with the combination of metformin plus a sulphonylurea. ${ }^{79}$ This presents a potential dilemma when considering the expansion of metformin use in CKD: the improved renal outcomes observed in the ADVANCE trial were achieved with a largely sulphonyureadriven protocol and so combination therapy could be argued to be the most evidence-based approach in this population. ${ }^{16} \mathrm{How}$ ever, despite the combination of metformin and a sulphonylurea being more frequent in the intensive control group of this study, an increase in mortality was not observed. Taken together with the results of other trials, the possibility of an adverse interaction between these agents remains uncertain. ${ }^{78}$

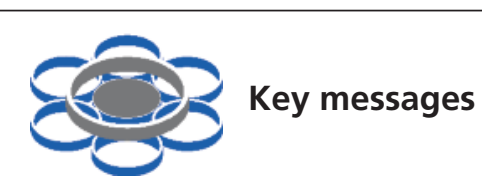

- More studies are required to establish the risks and benefits of using metformin in those with CKD

- The risk of lactic acidosis with metformin is low and it usually occurs in combination with other factors. Measures such as dose reduction and avoidance in those at particular risk may reduce the incidence of lactic acidosis further and allow the use of metformin to be expanded in those with advanced CKD

- Greater use of metformin in this high-risk population may result in improved cardiovascular outcomes, enhanced glycaemic control and a reduced risk of hypoglycaemia

\section{Discussion}

The absolute risk of lactic acidosis with metformin use is low. In CKD this risk is probably increased, but epidemiological evidence suggests that the overall incidence remains low. The excess risk may, in part, be circumstantial because CKD is associated with other factors that predispose to lactic acidosis. However, discontinuing metformin in this group of patients needs to be balanced against the advantages of metformin over other treatment options. Those with CKD and diabetes are at high risk of CVD, and metformin could be especially beneficial for these patients because, in contrast to other hypoglycaemic drugs, metformin may reduce cardiovascular risk. Furthermore, the alternative to continuing metformin is often to switch to a sulphonylurea or insulin, both of which are associated with weight gain and hypoglycaemic episodes. It is reasonable therefore to question whether it is better to accept the small risk of lactic acidosis with continuing metformin than the morbidity and mortality that may come with switching to an alternative hypoglycaemic agent.

There is a lack of objective outcome data to guide the use of metformin in the CKD population itself and further studies are needed. The existing evidence is largely extrapolated from studies involving participants with normal or mildly impaired renal function. Furthermore, the improved cardiovascular outcomes observed in the UKPDS were confined to those who were overweight. As such, it could be argued that there are insufficient data to support the initiation of metformin in all type 2 diabetics with advanced CKD. However, for the majority of patients with $C K D$, the question is not whether to start metformin but whether to continue. In patients who have been well maintained on metformin, particularly those who are overweight, the evidence is not strong enough to support its routine withdrawal upon reaching an eGFR of $30 \mathrm{~mL} / \mathrm{min}$, as per current guidelines. Indeed, other authors have put forward the case for metformin to be continued with lower levels of renal function and there is some evidence that this reflects current clinical practice. ${ }^{80-83}$ In our experience, many prescribers adopt a pragmatic approach 
and continue metformin until eGFR falls below $20 \mathrm{~mL} / \mathrm{min}$ or less, depending on patient age, weight, stability and co-morbidities. Recent observational data have suggested that continuing metformin beyond this may be associated with adverse outcomes, and so it is difficult to justify continued use in those with an eGFR of $<20 \mathrm{~mL} / \mathrm{min}$ except in the context of a clinical trial.

A sensible strategy for the extended use of metformin in CKD might be to reduce the prescribed dose of metformin, with close attention to risk factors for developing lactic acidosis such as heart failure and the risk of AKI. Given that patients with CKD are more likely to develop AKI, they should be fully informed of the risk associated with metformin and advised to have a lower threshold to seek medical advice should they become unwell. This situation is similar to that of inhibitors of the renin-angiotensin system, which are associated with a higher risk of hyperkalaemia and renal injury, and so should be withheld in the face of acute intercurrent illness.

\section{Conflict of interest None. Funding None.}

\section{References}

1 New JP, Middleton RJ, Klebe B, et al. Assessing the prevalence, monitoring and management of chronic kidney disease in patients with diabetes compared to those without diabetes in general practice. Diabet Med 2007;24:364-9. http://dx.doi.org/10.1111/j.1464-5491.2007.02075.x

2 Gilg J, Pruthi R, Fogarty D. UK Renal Registry 17th Annual Report: Chapter 1, UK Renal Replacement Therapy Incidence in 2013: National and Centre-specific Analyses. Bristol: UK Renal Registry 2014.

3 Ritz, E, Wolf G. Pathogenesis, clinical manifestations, and natural history of diabetic nephropathy. In: Floege J, Johnson RJ, Feehally J (eds) Comprehensive Clinical Nephrology, 4th Edition. St Louis: Saunders Elsevier, 2014: 359-78

4 Sarwar N, Gao P, Seshasai SR, et al. Diabetes mellitus, fasting blood glucose concentration, and risk of vascular disease: a collaborative metaanalysis of 102 prospective studies. Lancet 2010;375:2215-22. http://dx.doi.org/10.1016/S0140-6736(10)60484-9

5 Go AS, Chertow GM, Fan D, et al. Chronic kidney disease and the risks of death, cardiovascular events, and hospitalisation. N Engl J Med 2004; 351:1296-305. http://dx.doi.org/10.1056/NEJMoa041031

6 International Diabetes Federation. Diabetes Atlas 2014, Sixth edition. Available from: http://www.idf.org/sites/default/files/EN_6E_Atlas_Full_ 0.pdf (accessed 29 Oct 2015).

7 National Institute for Health and Care Excellence. The management of type 2 diabetes [CG87]. London: National Institute for Health and Care Excellence, 2009.

8 American Diabetes Association. Standards of medical care in diabetes. Diabetes Care 2014;37(Suppl 1):S14-80 http://dx.doi.org/10.2337/dc14-S014

9 British Medical Association and the Royal Pharmaceutical Society of Great Britain. British National Formulary 69: March 2015-September 2015. London: BMJ Publishing Group, 2015.

10 Hung SC, Chang YK, Liu JS, et al. Metformin use and mortality in patients with advanced chronic kidney disease: national, retrospective, observational, cohort study. Lancet Diabetes Endocrinol 2015:3:605-14. http://dx.doi.org/10.1016/\$2213-8587(15)00123-0

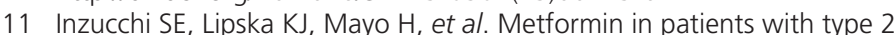
diabetes and kidney disease: a systemic review. JAMA 2014;312:266875. http://dx.doi.org/10.1001/jama.2014.15298

12 Lalau JD, Arnouts P, Sharif A, et al. Metformin and other antidiabetic agents in renal failure patients. Kidney Int 2014;87:308-22. http://dx.doi.org/10.1038/ki.2014.19

13 Bailey CJ, Turner RC. Metformin. N Engl J Med 1996;334:574-9. http://dx.doi.org/10.1056/NEJM199602293340906
14 UK Prospective Diabetes Study (UKPDS) Group. Intensive blood-glucose control with sulphonylureas or insulin compared with conventional treatment and risk of complications in patients with type 2 diabetes (UKPDS 33). Lancet 1998;352:837-53 http://dx.doi.org/10.1016/S0140-6736(98)07019-6

15 Holman RR, Paul SK, Bethel MA, et al.10-year follow-up of intensive glucose control in type 2 diabetes. N Engl J Med 2008;359:1577-89. http://dx.doi.org/10.1056/NEJMoa0806470

16 The ADVANCE Collaborative Group, Patel A, MacMahon S, et al. Intensive blood glucose control and vascular outcomes in patients with type 2 diabetes. N Engl J Med 2008;358:2560-72.

http://dx.doi.org/10.1056/NEJMoa0802987

17 Perkovic V, Heerspink HL, Chalmers J, et al. Intensive glucose control improves kidney outcomes in patients with type 2 diabetes. Kidney Int 2013;83:517-23. http://dx.doi.org/10.1038/ki.2012.401

18 Duckworth W, Abraira C, Moritz T, et al. Glucose control and vascular complications in veterans with type 2 diabetes. N Engl J Med 2009; 360:129-39. http://dx.doi.org/10.1056/NEJMoa0808431

19 Shurraw S, Hemmelgarn B, Lin M, et al. Association between glycemic control and adverse outcomes in people with diabetes mellitus and chronic kidney disease: a population-based cohort study. Arch Intern Med 2011;171:1920-7. http://dx.doi.org/10.1001/archinternmed.2011.537

20 Oomichi T, Emoto M, Tabata T, et al. Impact of glycemic control on survival of diabetic patients on chronic regular hemodialysis: a 7-year observational study. Diabetes Care 2006;29:1496-500. http://dx.doi.org/10.2337/dc05-1887

21 Drechsler C, Krane V, Ritz E, et al. Glycemic control and cardiovascular events in diabetic hemodialysis patients. Circulation 2009;120:2421-8. http://dx.doi.org/10.1161/CIRCULATIONAHA.109.857268

22 Food and Drug Administration. Glucophage (metformin hydrochloride) final printed labeling. Food and Drug Administration 2001, US Department of Health and Human Services. Available from: http://www.accessdata.fda.gov/drugsatfda_docs/nda/2000/20357S019_Glucophage_prntl bl.pdf (accessed 9 June 2015).

23 Tuttle KR, Bakris GL, Bilous RW, et al. Diabetic kidney disease: a report from an ADA consensus conference. Diabetes Care 2014;37:2864-83. http://dx.doi.org/10.2337/dc14-1296

24 Dreyer G, Hull S, Aitken Z, et al. The effect of ethnicity on the prevalence of diabetes and associated chronic kidney disease. Q J Med 2009;102 261-9. http://dx.doi.org/10.1093/qjmed/hon177

25 Bailey RA, Wang Y, Zhu V, et al. Chronic kidney disease in US adults with type 2 diabetes: an updated national estimate of prevalence based on Kidney Disease: Improving Global Outcomes (KDIGO) staging. BMC Res Notes 2014:2:415. http://dx/doi/org/10.1186/1756-0500-7-415.

26 Rodriquez-Poncelas A, Garre-Olmo J, Franch-Nadal J, et al. Prevalence of chronic kidney disease in patients with type 2 diabetes in Spain: PERCEDIME2 study. BMC Nephrol 2013;14:46. http://dx.xoi.org/10.1186/1471-2369-14-46.

27 UK Prospective Diabetes Study (UKPDS) Group. Effect of intensive bloodglucose control with metformin on complications in overweight patients with type 2 diabetes (UKPDS 34). Lancet 1998;352:854-65. http://dx.doi.org/10.1016/S0140-6736(98)07037-8

28 Saenz A, Fernandez-Esteban I, Mataix A, et al. Metformin monotherapy for type 2 diabetes mellitus. Cochrane Database of Systematic Reviews 2005;3:CD002966. http://dx.doi.org/10.1002/ 14651858.cd002966.pub3

29 Cryer DR, Nicholas SP, Henry DH, et al. Comparative outcomes study of metformin intervention versus conventional approach: the COSMIC approach study. Diabetes Care 2005;28:539-43. http://dx.doi.org/10.2337/diacare.28.3.539

30 Kahn SE, Haffner SM, Heise MA, et al. Glycemic durability of rosiglitazone, metformin, or glyburide monotherapy. N Engl J Med 2006; 355:2427-43. http://dx.doi.org/10.1056/NEJMoa066224

31 Nag S, Bilous R, Kelly W, et al. All-cause and cardiovascular mortality in diabetic subjects increases significantly with reduced estimated glomerular filtration rate (eGFR): 10 years' data from the South Tees Diabetes Mortality study. Diabet Med 2007;24:10-17. http://dx.doi.org/10.1111/j.1464-5491.2007.02023.x

32 Rodriguez-Poncelas A, Coll-De Tuero G, Turrò-Garriga O, et al. Impact of chronic kidney disease on the prevalence of cardiovascular disease in patients with type 2 diabetes in Spain: PERCEDIME2 study. BMC Nephrol 
2014;15:150. http://dx/doi.org/10.1186/1471-2369-15-150

33 Cea Soriano L, Johansson S, Stefansson B, et al. Cardiovascular events and all-cause mortality in a cohort of 57,946 patients with type 2 diabetes: associations with renal function and cardiovascular risk factors. Cardiovasc Diabetol 2015;14:38 http://dx.doi.org/10.1186/s12933-015-0204-5

34 Ekström N, Schiöler L, Svensson AM, et al. Effectiveness and safety of metformin in 51675 patients with type 2 diabetes and different levels of renal function: a cohort study from the Swedish National Diabetes Register. BMJ Open 2012;2:e001076. http://dx.doi.org/10.1136/bmjopen-2012-001076

35 Hong J, Zhang Y, Lai S, et al. Effects of metformin versus glipizide on cardiovascular outcomes in patients with type 2 diabetes and coronary artery disease. Diabetes Care 2013;36:1304-11. http://dx.doi.org/10.2337/ dc12-0719

36 Roussel R, Travert F, Pasquet B, et al. Metformin use and mortality among patients with diabetes and atherothrombosis. Arch Intern Med 2010;170:1892-9. http://dx.doi.org/10.1001/archinternmed.2010.409

37 Bodmer M, Meier C, Krähenbühl S, et al. Metformin, sulfonylureas, or other antidiabetes drugs and the risk of lactic acidosis or hypoglycemia: a nested case-control analysis. Diabetes Care 2008;31:2086-91. http://dx.doi.org/10.2337/dc08-1171

38 The Action to Control Cardiovascular Risk in Type 2 Diabetes Group. Effects of intensive glucose lowering in type 2 diabetes. $N$ Engl J Med 2008;358:2545-59. http://dx.doi.org/10.1056/NEJMoa0802743

39 Khunti K, Davies M, Majeed A, et al. Hypoglycaemia and risk of cardiovascular disease and all-cause mortality in insulin-treated people with type 1 and type 2 diabetes: a cohort study. Diabetes Care 2015;38:31622. http://dx.doi.org/10.2337/dc14-0920

40 Moen MF, Zhan M, Van Doren $\mathrm{H}$, et al. Frequency of hypoglycaemia and its significance in chronic kidney disease. Clin J Am Soc Nephrol 2009;4:1121-7. http://dx.doi.org/10.2215/CJN.00800209

41 MacGregor MS, Taal MW. Detection, Monitoring and Care of Patients with CKD. UK Renal Association, 2011. Available from: http://www.renal.org/guidelines/modules/detection-monitoring-andcare-of-patients-with-ckd\#downloads (accessed 14 July 2015).

42 National Kidney Foundation. KDOQI Clinical Practice Guideline for Diabetes and CKD: 2012 update. Am J Kidney Dis 2012;60:850-86. http://dx.doi.org/10.1053/j.ajkd.2012.07.005

43 Papademetriou V, Lovato L, Doumas M, et al. Chronic kidney disease and intensive glycemic control increase cardiovascular risk in patients with type 2 diabetes. Kidney Int 2015;87:649-59.

http://dx.doi.org/10.1038/ki.2014.296

44 Hung AM, Roumie CL, Greevy RA, et al. Kidney function decline in metformin versus sulfonylurea initiators: assessment of time-dependent contribution of weight, blood pressure, and glycemic control. Pharmacoepidemiol Drug Saf 2013;22:623-31. http://dx.doi.org/10.1002/pds.3432

45 Currie CJ, Poole CD, Gale EA. The influence of glucose-lowering therapies on cancer risk in type 2 diabetes. Diabetologia 2009;52:1766-77. http://dx.doi.org/10.1007/s00125-009-1440-6

46 Lago RM, Singh PP, Nesto RW. Congestive heart failure and cardiovascular death in patients with prediabetes and type 2 diabetes given thiazolidinediones: a meta-analysis of randomized clinical trials. Lancet 2007;370:112936. http://dx.doi.org/10.1016/S0140-6736(07)61514-1

47 Levin D, Bell S, Sund R, et al. Pioglitazone and bladder cancer risk: a multipopulation pooled, cumulative exposure analysis. Diabetologia 2015:58:493-504. http://dx.doi.org/10.1007/s00125-014-3456-9

48 Abdelmoneim AS, Eurich DT, Light PE, et al. Cardiovascular safety of sulphonylureas: over 40 years of continuous controversy without an answer. Diabetes Obes Metab 2015:17:523-32.

http://dx.doi.org/10.1111/dom.12456

49 Gamble JM, Simpson SH, Eurich DT, et al. Insulin use and increased risk of mortality in type 2 diabetes: a cohort study. Diabetes Obes Metab 2010:12:47-53. http://dx.doi.org/10.1111/j.1463-1326.2009.01125.x

50 de Jager J, Kooy A, Lehert $\mathrm{P}$, et al. Long term treatment with metformin in patients with type 2 diabetes and risk of vitamin B-12 deficiency: randomised placebo controlled trial. BMJ 2010;340:c2181. http://dx.doi.org/10.1136/bmi.c2181

51 Liu F, Lu JX, Tang JL, et al. Relationship of plasma creatinine and lactic acid in type 2 diabetic patients without renal dysfunction. Chin Med J (Engl) 2009;122:2547-53

52 Mongraw-Chaffin ML, Matsushita K, Brancati FL, et al. Diabetes medication use and blood lactate level among participants with type 2 diabetes: the atherosclerosis risk in communities carotid MRI study. PLoS One 2012;7:e51237. http://dx.doi.org/10.1371/journal.pone.0051237.

53 Davis TM, Jackson D, Davis WA, et al. The relationship between metformin therapy and the fasting plasma lactate in type 2 diabetes: The Fremantle Diabetes Study. Br J Clin Pharmacol 2011;52:137-44. http://dx.doi.org/10.1046/j.0306-5251.2001.01423.x

54 Salpeter SR, Greyber E, Pasternak GA, et al. Risk of fatal and nonfatal lactic acidosis with metformin use in type 2 diabetes mellitus. Cochrane Database of Systematic Reviews 2010;4:CD002967.

http://dx.doi.org/10.1002/14651858.cd002967.pub3

55 Stang M, Wysowski DK, Butler-Jones D. Incidence of lactic acidosis in metformin users. Diabetes Care 1997;22:925-7. http://dx.doi.org/10.2337/diacare.22.6.925

56 Brown JB, Pedula K, Barzilay J, et al. Lactic acidosis rates in type 2 diabetes. Diabetes Care 1998:21:1659-63. http://dx.doi.org/10.2337/diacare.21.10.1659

57 Richy FF, Sabidó-Espin M, Guedes S, et al. Incidence of lactic acidosis in patients with type 2 diabetes with and without renal impairment treated with metformin: a retrospective cohort study. Diabetes Care 2014;37:2291-5.http://dx.doi.org/10.2337/dc14-0464

58 Eppenga WL, Lalmohamed A, Geerts AF, et al. Risk of lactic acidosis or elevated lactate concentrations in metformin users with renal impairment: a population-based cohort study. Diabetes Care 2014;37:221824. http://dx.doi.org/10.2337/dc13-3023

59 Sambol NC, Chiang J, Lin ET, et al. Kidney function and age are both predictors of pharmacokinetics of metformin. J Clin Pharmacol 1995; 35:1094-102. http://dx.doi.org/10.1002/j.1552-4604.1995.tb04033.x

60 Frid A, Sterner GN, Löndahl M, et al. Novel assay of metformin levels in patients with type 2 diabetes and varying levels of renal function: clinical recommendations. Diabetes Care 2010;33:1291-3.

http://dx.doi.org/10.2337/dc09-1284

61 Wilcock C, Bailey CJ. Accumulation of metformin by tissues of the normal and diabetic mouse. Xenobiotica 1994;24:49-57. http://dx.doi.org/10.3109/00498259409043220

62 Kajbak F, Bennis Y, Hurtel-Lemaire AS, et al. Unexpectedly long half-life of metformin elimination in cases of metformin accumulation. Diabet Med 2016;33:105-10. http://dx.doi.org/10.1111/dme.12959

63 Stades AME, Heikens JT, Erkelens DW, et al. Metformin and lactic acidosis: cause or coincidence? A review of case reports. J Intern Med 2004;255:179-87. http://dx.doi.org/10.1046/j.1365-2796.2003.01271.x

64 Kamber N, Davis WA, Bruce DG, et al. Metformin and lactic acidosis in an Australian community setting: the Fremantle Diabetes Study. Med J Aust 2008; 188:446-9.

65 van Berlo-van de Laar IR, Vermeij CG, Doorenbos CJ. Metformin associated lactic acidosis: incidence and clinical correlation with metformin serum concentration measurements. J Clin Pharm Ther 2011;36:37682. http://dx.doi.org/10.1111/j.1365-2710.2010.01192.x

66 Rachmani R, Slavachevski I, Levi Z, et al. Metformin in patients with type 2 diabetes mellitus: reconsideration of traditional contraindications. Eur J Intern Med 2002;13:428. http://dx.doi.org/10.1016/S0953-6205(02)00131-0

67 Lim VC, Sum CF, Chan ES, et al. Lactate levels in Asian patients with type 2 diabetes mellitus on metformin and its association with dose of metformin and renal function. Int J Clin Pract 2007;61:1829-33. http://dx.doi.org/10.1111/j.1742-1241.2007.01487.x

68 Connolly V, Kesson CM. Metformin treatment in NIDDM patients with mild renal impairment. Postgrad Med J 1996;72:352-4. http://dx. doi.org/10.1136/pgmj.72.848.352

69 Lalau JD, Vermersch A, Hary L, et al. Type 2 diabetes in the elderly: an assessment of metformin (metformin in the elderly). Int J Clin Pharmacol Ther Toxicol 1990;28:329-32.

70 Lin YC, Lin LY, Wang HF, et al. Fasting plasma lactate concentrations in ambulatory elderly patients with type 2 diabetes receiving metformin therapy: a retrospective cross-sectional study. J Chin Med Assoc 2010;73:617-22. http://dx.doi.org/10.1016/S1726-4901(10)70135-0

71 Duong JK, Roberts DM, Furlong TJ, et al. Metformin therapy in patients with chronic kidney disease. Diabetes Obes Metab 2012;14:963-5. 
http://dx.doi.org/10.1111/j.1463-1326.2012.01617.x

72 Al-Hwiesh AK, Abdul-Rahman IS, El-Deen MA, et al. Metformin in peritoneal dialysis: a pilot experience. Perit Dial Int 2014;34:368-75. http://dx.doi.org/10.3747/pdi.2013.00048

73 Lalau JD, Race JM. Lactic acidosis in metformin-treated patients. Prognostic value of arterial lactate levels and plasma metformin concentrations. Drug Saf 1999;20:377-84.

http://dx.doi.org/10.2165/00002018-199920040-00006

74 James MT, Hemmelgarn BR, Wiebe N, et al. Glomerular filtration rate, proteinuria, and the incidence and consequences of acute kidney injury: a cohort study. Lancet 2010;376:2096-103.

http://dx.doi.org/10.1016/S0140-6736(10)61271-8

75 Pantalone KM, Kattan MW, Yu C, et al. Increase in overall mortality risk in patients with type 2 diabetes receiving glipizide, glyburide or glimepiride monotherapy versus metformin: a retrospective analysis. Diabetes Obes Metab 2012;14:803-09.

http://dx.doi.org/10.1111/j.1463-1326.2012.01604.x

76 Wheeler S, Moore K, Forsberg CW, et al. Mortality among veterans with type 2 diabetes initiating metformin, sulfonylurea or rosiglitazone monotherapy. Diabetologia 2013;56:1934-43. http://dx.doi.org/10.1007/s00125-013-2958-1

77 Boussageon R, Gueyffier F, Cornu C. Metformin as firstline treatment for type 2 diabetes: are we sure? BMJ 2016:352:h6748. http://dx.doi.org/10.1136/bmj.h6748

78 Boussageon R, Supper I, Bejan-Angoulvant T, et al. Reappraisal of metformin efficacy in the treatment of type 2 diabetes: a meta-analysis of randomised controlled trials. PLOS Med 2012:9:e1001204. http://dx.doi.org/10.1371/journal.pmed.1001204

79 Rao AD, Kuhadiya N, Reynolds K, et al. Is the combination of sulfonylureas and metformin associated with an increased risk of cardiovascular disease or all-cause mortality? Diabetes Care 2008;31:1672-8. http://dx.doi.org/10.2337/dc08-0167

80 Chowdhury TA, Wright R, Yaqoob MM. Using metformin in the presence of renal disease: current guidelines are too restrictive, and many patients who could benefit are missing out. BMJ 2015;349:h1758. http://dx.doi.org/10.1136/bmj.h1758

81 Nye HJ, Herrington WG. Metformin: the safest hypoglycaemic agent in chronic kidney disease? Nephron Clin Pract 2011;118:380-3. http://dx.doi.org/10.1159/000323739

82 Anon. Metformin OK in CKD? Drugs Therapeutic Bulletin 2014:52:37. http://dx.doi.org/10.1136/dtb.2014.4.0244

83 Christiansen CF, Ehrenstein V, Heide-Jørgensen U, et al. Metformin initiation and renal impairment: a cohort study in Denmark and the UK. BMJ Open 2015;5:e008531. http://dx.doi.org/10.1136/bmjopen-2015008531
We've come

together to deliver:

\section{THE WORLD'S}

PREMIER DIABETES

MANAGEMENT PLATFORM

glooko + diasend. 